\title{
Modeling Exchange Rate Volatility Dynamics of the Great Britain Pound to Ethiopian Birr Using the Semi-Parametric Non-Linear Fuzzy-EGARCH-ANN Model
}

\author{
Geleta T. Mohammed ${ }^{*}$, Jane A. Aduda², Ananda 0. Kube ${ }^{3}$ \\ ${ }^{1}$ Mathematics Department, Pan African University (PAU), Nairobi, Kenya \\ ${ }^{2}$ Mathematics Department, Jomo Kenyatta University, Nairobi, Kenya \\ ${ }^{3}$ Mathematics Department, Kenyatta University, Nairobi, Kenya \\ Email: *geletah2016@gmail.com
}

How to cite this paper: Mohammed, G.T., Aduda, J.A. and Kube, A.O. (2020) Modeling Exchange Rate Volatility Dynamics of the Great Britain Pound to Ethiopian Birr Using the Semi-Parametric Non-Linear Fuzzy-EGARCH-ANN Model. Journal of Mathematical Finance, 10, 598-611. https://doi.org/10.4236/jmf.2020.104035

Received: September 29, 2020

Accepted: October 20, 2020

Published: October 23, 2020

Copyright $\odot 2020$ by author(s) and Scientific Research Publishing Inc. This work is licensed under the Creative Commons Attribution International License (CC BY 4.0) http://creativecommons.org/licenses/by/4.0/

\begin{abstract}
In this paper, a robust analysis of volatility forecasting of the GBP-ETB exchange rate was provided using weekly data spanning the period June 30 , 2003-January 24, 2020. To our knowledge, this was the first study that focuses on the GBP-ETB exchange rate using high-frequency data and the FuzzyEGARCH-ANN econometric model. The research finds that the best performing model in terms of one-step ahead forecasts based on realized volatility computed from the underlying daily data series is the Fuzzy-EGARCH$\operatorname{ANN}(1,2,2,1)$ with students $t$-distribution.
\end{abstract}

\section{Keywords}

Volatility Forecasting, ARCH, EGARCH, ANN, Semi-Parametric Non-Linear Fuzzy-EGARCH-ANN Model

\section{Introduction}

The variation of the price at which currencies of two different countries are traded is known as exchange rate volatility [1]. Because exchange rate volatility is synonymous with risk and uncertainty, it is the main source of concern for macro-economic policymakers. The sensitivity of internationally-oriented countries to foreign exchange rate volatility is well documented [2]. For the design of a well-informed policy that seeks to minimize the harmful impact of uncertainty on the national welfare, the well-understanding of the dynamics of volatility is very important. 
In financial risk management and portfolio construction, the wide use of exchange rate volatility models by business analysts and commercial strategists is crucial from a microeconomic perspective. In addition to this, for international traders' export and import decisions forecasting the volatility of the foreign exchange rate has good importance. Hence, exchange rate volatility causes risk-averse traders to reduce their transaction because of the high unpredictability of their profits. By contrast, risk-takers could benefit from seeking out hedging opportunities. Moreover, for international investors who require portfolio diversification beyond their national border accurate volatility forecasting is critical.

In addition to the previous discussion, the study has conducted a robust case study research on volatility forecasting using weekly GBP-ETB exchange rates. In particular, we try to examine the capability of the Fuzzy-EGARCH-ANN model to capture stylized features of volatility clustering, persistence, and leverage effects. Moreover, the study has tried to evaluate the forecasting performance of the Fuzzy-EGARCH-ANN model.

Because of the current exchange rate system classified as a crawling peg to the USA, i.e. a managed float, formally determined USD-ETB exchange rate variation does not fully capture the extent of currency volatility. This has motivated our choice of using GBP-ETB. This is because Euro-area countries, the USA, and the United Kingdom are the main trading partners of Ethiopia. Furthermore, by using high frequency (i.e. weekly) data, the study has avoided the danger of averaging-out volatility episodes that characterize studies based on yearly data. It is also cost noting that using weekly data removes the need to construct real exchange rate which depends on having accurate domestic and foreign price devalues.

As explained previously, the volatility of the exchange rate affects policymakers as well as investors. Hence, the importance of exchange rate volatility studies cannot be overestimated. Many researchers including [3] [4] [5] modeled exchange rate volatility using GARCH type models, but without offering insight on their models. de Dieu Ntawihebasenga et al. [6] modeled volatility of exchange rate in Rwandese markets using symmetric GARCH models ignoring asymmetric models. To the best of my knowledge, no research has been done on forecasting volatility of weekly GBP-ETB exchange rate using the Fuzzy-EGARCHANN model, and robust forecast evaluation techniques. Hence, the present study contributes to the literature by bridging the existing knowledge gap on volatility forecasting in Ethiopia.

The general objective of the study is to forecast the volatility of GBP-ETB exchange rates using the Fuzzy-EGARCH-ANN model. Individually to assess the patterns of GBP-ETB exchange rate volatility, explore as the Fuzzy-EGARCH-ANN model is capturing the behavior of volatility of GBP-ETB exchange rate, and evaluate the volatility forecasting power of the Fuzzy-EGARCH-ANN model.

The paper is organized into four sections. Not together from the introduction in Section 1, Research Methodology is presented in Section 2. In Section 3 detail of results and discussion is given. In Section 4, a Summary and conclusion part of this study is presented. 


\section{Research Methodology}

\subsection{Data Source}

To achieve the objective of the study, weekly GBP-ETB exchange rates data were collected from the National Bank of Ethiopia. In the literature, a statistical test of model's forecast performance is commonly conducted by splitting a given data set into an in-sample period, which are used for initial parameter estimation and model selection; and out-sample period, which is used to evaluate forecast performance. In this study, the in-sample period runs from June 30, 2003, to November 24, 2018 (800 observations), whereas the out-of-sample period runs from November 25, 2018, to January 24, 2020 (65 observations).

\subsection{Model Specification and Econometric Tests}

\subsubsection{Unit Root Test of the Variables}

There are many tests for determining whether a time series is stationary or nonstationary. The ones used in the present study are the Augmented Dickey-Fuller (ADF) test [7] and the Phillips-Perron (PP) test [8]. The presence of conditional heteroscedasticity is referred to as the ARCH effects. Ljung-Box statistics $Q(m)$ and Lagrange Multiplier (LM) tests are the appropriate $\mathrm{ARCH}$ effects tests and were used in this study. Ljung-Box test statistic $(Q)$ was used to assess the independency among the residuals [9]. When dealing with ARCH/GARCH-type models, we first examine the characteristics of the unconditional distribution of the exchange rate. This will enable us to explore and explain some stylized facts that exist in the financial time series. In statistics, the Bera and Jarque [10] test is a test of departure from normality based on the sample skewness and kurtosis [9].

\subsubsection{Fuzzy-EGARCH-ANN Model}

The Fuzzy-EGARCH-ANN model is described by a collection of fuzzy rules in the form of If-Then statements in order to describe the stock fluctuations with volatility clustering overlooked by EGARCH-ANN model via Fuzzy rules and the asymmetric responses of volatility to positive and negative shocks via an EGARCH-ANN model [11].

The $k^{\text {th }}$ rule of the fuzzy system for $\operatorname{EGARCH-ANN}(p, q, m, s)$ model is described by:

$$
\begin{aligned}
& \text { Rule }^{k}: \text { if } x_{1}^{t} \text { is } F_{k 1} \text { and } \cdots x_{d}^{t} \text { is } F_{k d} \text {, then } \\
& y_{k t}=\sigma_{k t} \epsilon_{k t} \\
& \qquad \begin{aligned}
\ln \sigma_{k t}^{2}= & E_{k}+\sum_{j=1}^{q} \beta_{k} j \ln \sigma_{t-j}^{2}+\sum_{i=1}^{p} \gamma_{k i}\left(\frac{\left|y_{t-i}\right|}{\sigma_{t-i}}-E\left(\frac{\left.\left|y_{t-i}\right|\right)}{\sigma_{t-i}}\right)\right) \\
& +\sum_{i=1}^{p} \alpha_{k i} \frac{y_{t-i}}{\sigma_{t-i}}+\sum_{h=1}^{s} \xi_{k h} G\left(Z_{t} W_{h}+w_{h, 0}\right)
\end{aligned}
\end{aligned}
$$

where

$$
G\left(Z_{t} W_{h}+w_{h, 0}\right)=\tanh \left(Z_{t} W_{h}+w_{h, 0}\right),
$$




$$
\begin{gathered}
W_{h}=\left(w_{h, 1}, \cdots, w_{h, m}\right)^{\prime}, \\
z_{t-d}=\frac{y_{t-d}-E(y)}{\sqrt{E\left(y^{2}\right)}}, d=1: m \\
x^{t}=\left[y_{t-1}, y_{t-2}, \cdots, y_{t-p}, \sigma_{t-1}^{2}, \sigma_{t-2}^{2}, \cdots, \sigma_{t-q}^{2}\right]^{\mathrm{T}}=\left[x_{1}^{t}, x_{2}^{t}, \cdots, x_{d}^{t}\right] .
\end{gathered}
$$

Here, $x^{t}$ is the input vector with $d=(p+q)$ at instance $t . F_{k l}$ is the fuzzy set to describe the stock market return and volatility for $l=1,2,3, \cdots, d, R$ is the number of rules, and $x_{l}^{t}$ is the premise variable. Plus, these things, the study has assumed that the distribution of residual series follows either the Gaussian Normal or student's $t$-distribution. That is, if it is not following the Gaussian Normal distribution, then it follows the student's $t$-distribution directly.

The output of this Fuzzy-EGARCH-ANN model is the weighted average of each individual rule and is obtained by using FIS fundamental steps as in [11] and [12] as follows:

Step 1 (Fuzzification layer): Using the Gaussian membership function, find the grade of membership of the input $x_{l}^{t}$ in $F_{k l}$ as follows:

$$
F_{k l}\left(x_{l}^{t}\right)=\exp \left[-\frac{1}{2}\left(\frac{x_{l}^{t}-c_{k l}}{a_{k l}}\right)^{2}\right]
$$

where $c_{k l}$ is the center and $a_{k l}$ is the spread of $k^{\text {th }}$ rule membership function corresponding to the $t^{\text {th }}$ premise variable.

Step 2 (Firing Strength Layer): Find the firing strength of $k^{\text {th }}$ rule by assuming the product T-norm of the antecedent fuzzy sets as:

$$
u_{k}\left(x^{t}\right)=\prod_{l=1}^{d} F_{k l}\left(x_{l}^{t}\right)=\prod_{l=1}^{d}\left[-\frac{1}{2}\left(\frac{x_{l}^{t}-c_{k l}}{a_{k l}}\right)^{2}\right]
$$

Step 3 (Normalization Layer): Finding the normalized firing strengths, i.e. the ratio of the $k^{\text {th }}$ rule's firing strength to the sum of all rule's firing strengths:

$$
\bar{w}_{k}=\frac{u_{k}\left(x^{t}\right)}{\sum_{k=1}^{R} u_{k}\left(x^{t}\right)}
$$

Step 4 (Consequent and Defuzzification Layer): Combine the normalized firing strengths and the corresponding rule consequent to produce the model output as the weighted average of each individual rule:

$$
\ln \sigma_{t}^{2}=\sum_{k=1}^{R} \bar{w}_{k} f_{k}
$$

where $f_{k}$ is the output of the $k^{\text {th }}$ rule. That is,

$$
\begin{aligned}
f_{k}= & E_{k}+\sum_{j=1}^{q} \beta_{k} j \ln \sigma_{t-j}^{2}+\sum_{i=1}^{p} \gamma_{k i}\left(\frac{\left|y_{t-i}\right|}{\sigma_{t-i}}-E\left(\frac{\left|y_{t-i}\right|}{\sigma_{t-i}}\right)\right) \\
& +\sum_{i=1}^{p} \alpha_{k i} \frac{y_{t-i}}{\sigma_{t-i}}+\sum_{h=1}^{s} \xi_{k h} G\left(Z_{t} W_{h}+w_{h, 0}\right)
\end{aligned}
$$

This implies that, 


$$
\ln \sigma_{t}^{2}=\sum_{k=1}^{R} \bar{w}_{k} f_{k}=\sum_{k=1}^{R}\left[\frac{u_{k}\left(x^{t}\right)}{\sum_{k=1}^{R} u_{k}\left(x^{t}\right)} f_{k}\right]
$$

Step 1 (Fuzzification layer): Using the Gaussian membership function, find the grade of membership of the input $x_{l}^{t}$ in $F_{k l}$ as follows:

$$
F_{k l}\left(x_{l}^{t}\right)=\exp \left[-\frac{1}{2}\left(\frac{x_{l}^{t}-c_{k l}}{a_{k l}}\right)^{2}\right]
$$

where $c_{k l}$ is the center and $a_{k l}$ is the spread of $k^{t h}$ rule membership function corresponding to the $I^{\text {th }}$ premise variable.

Step 2 (Firing Strength Layer): Find the firing strength of $k^{\text {th }}$ rule by assuming the product $\mathrm{T}$-norm of the antecedent fuzzy sets as:

$$
u_{k}\left(x^{t}\right)=\prod_{l=1}^{d} F_{k l}\left(x_{l}^{t}\right)=\prod_{l=1}^{d}\left[-\frac{1}{2}\left(\frac{x_{l}^{t}-c_{k l}}{a_{k l}}\right)^{2}\right]
$$

Step 3 (Normalization Layer): Finding the normalized firing strengths, i.e. the ratio of the $k^{\text {th }}$ rule's firing strength to the sum of all rule's firing strengths:

$$
\bar{w}_{k}=\frac{u_{k}\left(x^{t}\right)}{\sum_{k=1}^{R} u_{k}\left(x^{t}\right)}
$$

Step 4 (Consequent and Defuzzification Layer): Combine the normalized firing strengths and the corresponding rule consequent to produce the model output as the weighted average of each individual rule:

$$
\ln \sigma_{t}^{2}=\sum_{k=1}^{R} \bar{w}_{k} f_{k}
$$

where $f_{k}$ is the output of the $k^{t h}$ rule. That is,

$$
\begin{aligned}
f_{k}= & E_{k}+\sum_{j=1}^{q} \beta_{k} j \ln \sigma_{t-j}^{2}+\sum_{i=1}^{p} \gamma_{k i}\left(\frac{\left|y_{t-i}\right|}{\sigma_{t-i}}-E\left(\frac{\left|y_{t-i}\right|}{\sigma_{t-i}}\right)\right) \\
& +\sum_{i=1}^{p} \alpha_{k i} \frac{y_{t-i}}{\sigma_{t-i}}+\sum_{h=1}^{s} \xi_{k h} G\left(Z_{t} W_{h}+w_{h, 0}\right)
\end{aligned}
$$

This implies that,

$$
\ln \sigma_{t}^{2}=\sum_{k=1}^{R} \bar{w}_{k} f_{k}=\sum_{k=1}^{R}\left[\frac{u_{k}\left(x^{t}\right)}{\sum_{k=1}^{R} u_{k}\left(x^{t}\right)} f_{k}\right]
$$

The collection of the $R$ rules assembles a model as a combination of local models. A local model contributes to the overall output which is proportional to the normalized degree of the firing of each rule. As a result, the exponential of this weighted average value gives us the predicted stock market return volatility using our newly proposed model [11].

\subsubsection{Choosing the Optimal Lag Length and Model Selection Criterion} The optimal lag length of the ARIMA and ARCH/GARCH type's model was 
chosen using the ACF, PACF plot, and information criteria. The PACF of a time series is a function of its ACF and is a useful tool for determining the order $\mathrm{p}$ of an AR model because PACF cuts off at lag $p$ for an $\operatorname{AR}(p)$ process. For MA models, ACF is useful in specifying the order because ACF cuts off at lag $q$ for an $\operatorname{MA}(q)$ [13]. Some of the more popular information criterion includes AIC and BIC are also used to select the appropriate models.

\subsubsection{Parameter Estimation}

Ordinary least squares (OLS) works great (assuming we meet some preliminary conditions), but one assumptions that must be made for OLS to work is that the disturbance term $\epsilon_{t}$ are homoscedastic. However, this is not always a very realistic assumption in real life, since variance is not always constant. Under the presence of ARCH effects, OLS estimation is not efficient. Therefore, the study employed maximum likelihood estimation (MLE) for estimating unknown parameters in EGARCH-ANN models.

The design of the Fuzzy-EGARCH-ANN model includes the determination of the unknown parameters, namely the parameters of the consequent parts of the fuzzy If-Then rules by minimizing the prediction error [11]. Therefore, to estimate the Fuzzy-EGARCH-ANN model parameters without suffering from local optimum, Differential Evolution (DE) algorithm with Archive is used [11]. Furthermore, step by step self-explanatory summary of the algorithm that we have used in this study is given by Table 1 . For your understanding, the software we have used throughout this study in MATLAB R2018a, where $c$ is a positive constant between 0 and $1, \operatorname{mean}_{A}($.$) is the usual arithmetic mean, \operatorname{mean}_{L}($.$) is the$ Lehmer mean and given by

$$
\text { mean }_{L}\left(S_{F}\right)=\frac{\sum_{F \in S_{F}} F^{2}}{\sum_{F \in S_{F}} F}
$$

\subsubsection{Realized Volatility Measures}

Realized volatility is defined as the sum of squared high frequency returns (such as intraday returns) and is a popular measure of volatility in empirical finance [9] and [15] [16]. The realized volatility models are calculated from high frequency data, intraday data. The measure of this realized volatility can be expressed as:

$$
R_{V t}=\sum_{i=1}^{m} Y_{t}^{2}
$$

where $Y_{t}^{2}$ the intra daily return square in the $m_{t h}$ interval. Similarly, in the case of this study, since we have no intra daily data, the realized variance of the weekly data set was computed using the daily data as follows:

$$
\sigma_{R_{V t}}^{2}=\frac{\sum_{i=1}^{m}\left(Y_{t}-\bar{Y}_{t}\right)^{2}}{m-1}
$$

where $Y_{t}$ is the daily returns of GBP-ETB exchange rate

$\left(Y_{t}=\log \left(P_{t}\right)-\log \left(P_{(t-1)}\right)\right)$ of the $m^{t h}$ days interval $(m=5)$ and $\bar{Y}_{t}$ is the average of return daily of GBP-ETB exchange rate and $m$ is the number of intervals 
of days.

\section{Results and Discussions}

The plot of the weekly Pound-ETB exchange rate for the period of June 30, 2003, to January 24, 2020, is shown in Figure 1. From this figure, it is evident that unconditional mean and variance are changing over time, and the series has an increasing trend over time. The changing mean and variance of Great Britain Pound-ETB exchange rate over time is an indication of the nonstationarity of the level series. This implies that it is difficult to model ARIMA and ARCH/GARCHtype models for nonstationary series. Therefore, in order to achieve stationary, logarithmic transformation was applied to the level series.

Table 1. Procedure of JADE with archive and its description:

Procedure of JADE with Archive as in [11] and [14]

Start

Initialize:

$\mu_{C R}=0.5 ; \mu_{F}=0.5 ; \quad \mathbf{A}=\varnothing ;$ and create a random initial population $\left\{X_{i, 0}: i=1: N P\right\}$

For $g=1: G$; Generation loop

$S_{F}=\varnothing ; S_{C R}=\varnothing ;$

For $i=1$ : NP; Population size loop

\section{Generate:}

$C R_{i}=\operatorname{randni}\left(\mu_{C R}, 0.1\right), \quad F_{i}=\operatorname{randci}\left(\mu_{F}, 0.1\right)$

Randomly choose:

$X_{\text {best, },}^{p}$ as one of the $100 p \%$ best vectors, $X_{r 1, g} \neq X_{i, g}$ from current population $\mathbf{P}$,

and $\tilde{X}_{r 2, g} \neq X_{r 1, g} \neq X_{i, g}$ from $\mathbf{P} \cup \mathbf{A}$.

Compute

$V_{i, g}=X_{i, g}+F_{i} *\left(X_{b e s t, g}^{p}-X_{i, g}\right)+F_{i} *\left(X_{r 1, g}-\tilde{X}_{r 2, g}\right)$

Generate:

$j_{\text {rand }}=\operatorname{randint}(1, D)$

For $j=1: D$ Dimension loop

If $j=j_{\text {rand }}$ or $\operatorname{rand}(0,1)<C R_{i}$ then $u_{j, i, q}=v_{j, i, q}$ Else $u_{j, i, q}=x_{j, i, g}$. End If

End for Dimension loop

If $E\left(X_{i, g}\right) \leq E\left(U_{i, g}\right)$ then $X_{i, g+1}=X_{i, g}$ Else $X_{i, g+1}=U_{i, g} ; X_{i, g} \rightarrow \mathbf{A} ; C R_{i} \rightarrow S_{C R}, \quad F_{i} \rightarrow S_{F}$.

End If

End for Population size loop

Randomly remove solutions from $\mathbf{A}$ so that the cardinal of $\mathbf{A}$ is less or equal to $N P$

$\mu_{C R}=(1-c) * \mu_{C R}+c * \operatorname{mean}_{\mathrm{A}}\left(S_{C R}\right)$

$\mu_{\mathrm{F}}=(1-c) * \mu_{\mathrm{F}}+c *$ mean $_{\mathrm{L}}\left(S_{\mathrm{F}}\right)$

End for Generation loop

End 


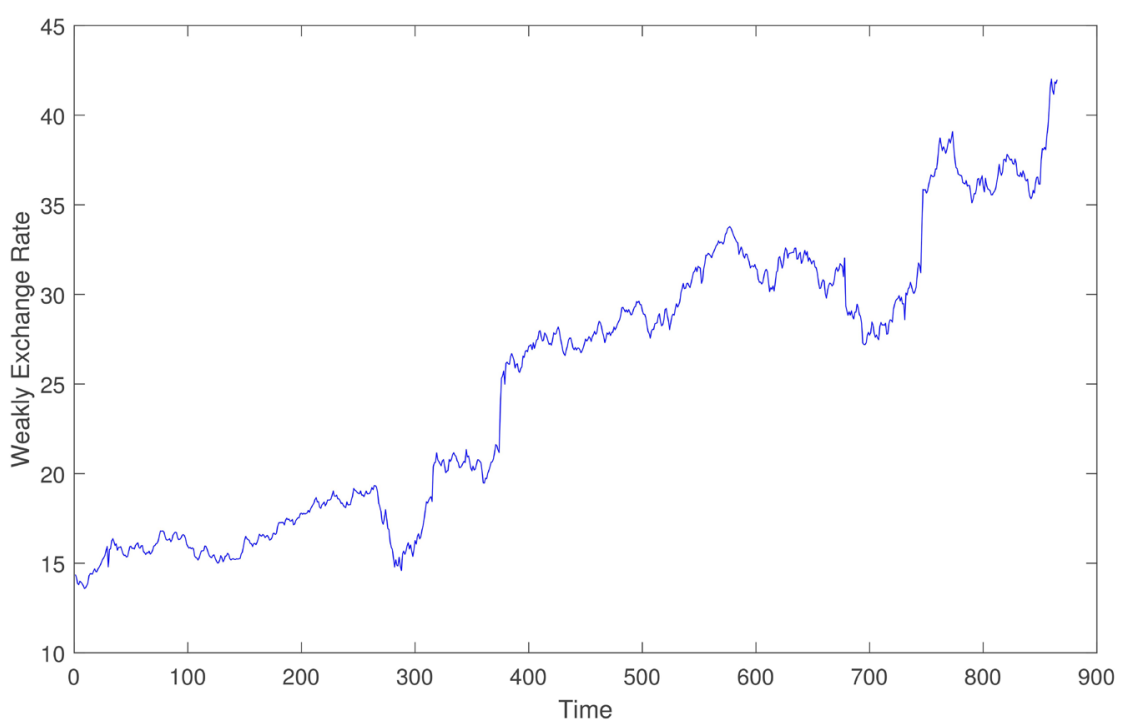

Figure 1. The weakly exchange rate series.

Table 2 presents the findings of the ADF test and PP test and formally confirms that the transformation of natural logarithms of Great Britain Pound-ETB exchange rate is stationary.

Table 2 portrays the ARCH effect tests on the residuals of $\operatorname{ARIMA}(0,0,0)$ model. These results show the presence of ARCH effects in the Great Britain Pound-ETB exchange rate. This suggests that modeling ARCH/GARCH types are appropriate for the data set. As result, the obtained basic statistical properties of this data are given by Table 2 .

\section{Note:}

- Mean < median usually flags left skewness.

- Negative skewness means left skewed data.

- Kurtosis > 3 means larger peakedness than Gaussian.

- Arch Test result with very small $p$-vlaue implies existence of strong heteroskedasticity.

- Jarquebera test result with very small $p$-value implies that the residual series strongly follows the student's $t$-distribution.

Furthermore, Figures 1-4 are the corresponding figures of the weakly pound to ETB exchange rate series, log return series, realized volatility series, residual series, and histogram of the residual series, respectively.

Now by using the first 800 (that is, for $T=800$ ) simulated data points, the study has obtained the following results. Since the study has identified as the residual series follows the student's $t$-distribution, then by using this distribution type EGARCH-ANN $(1,2,2,1)$ model is obtained as the best fitted model to this selected data. Moreover, its fitness summary has presented by Table 3 .

With addition informations like Log Likelihood: 2655, Akaike Information Criteron: -5296 Bayesian Information Criteron: -5263 Hannan-Quinn Information Criteron: -5283 . 
Table 2. Statistical properties of weakly log return data.

\begin{tabular}{cc}
\hline \multicolumn{2}{c}{ Statistical properties of Weakly log Return data } \\
Min. & -0.087221 \\
Max. & 0.112205 \\
Mean & 0.001240 \\
Median & 0.000924 \\
Variance & 0.000187 \\
Skewness & 1.137371 \\
Kurtosis & 16.288923 \\
Arch test & $p$-Value $=8.0384 \mathrm{e}-09$ \\
Jarque-Bera test (for alpha $=0.05)$ & $p$-value $=4.4409 \mathrm{e}-16$ \\
ADF test & $p$-Value $=1.0000 \mathrm{e}-03$ \\
PP test & $p$-Value $=1.0000 \mathrm{e}-03$ \\
\hline
\end{tabular}

Table 3. The EGARCH-ANN $(1,2,2,1)$ model fitted to the given data.

\begin{tabular}{cccc}
\hline Parameters & Coefficients & Std Errors & $t$-stats \\
\hline K & -0.3398 & 0.1388 & -2.4487 \\
ARCH1 & 0.2496 & 0.0536 & 4.6541 \\
GARCH1 & 0.2790 & 0.1341 & 2.0806 \\
GARCH2 & 0.6781 & 0.1350 & 5.0217 \\
Leverage1 & -0.0661 & 0.0341 & -1.9402 \\
Leverage by ANN1 & 0.3053 & 0.1453 & 2.1017 \\
DoF & 4.7485 & 0.6898 & 6.8839 \\
\hline
\end{tabular}

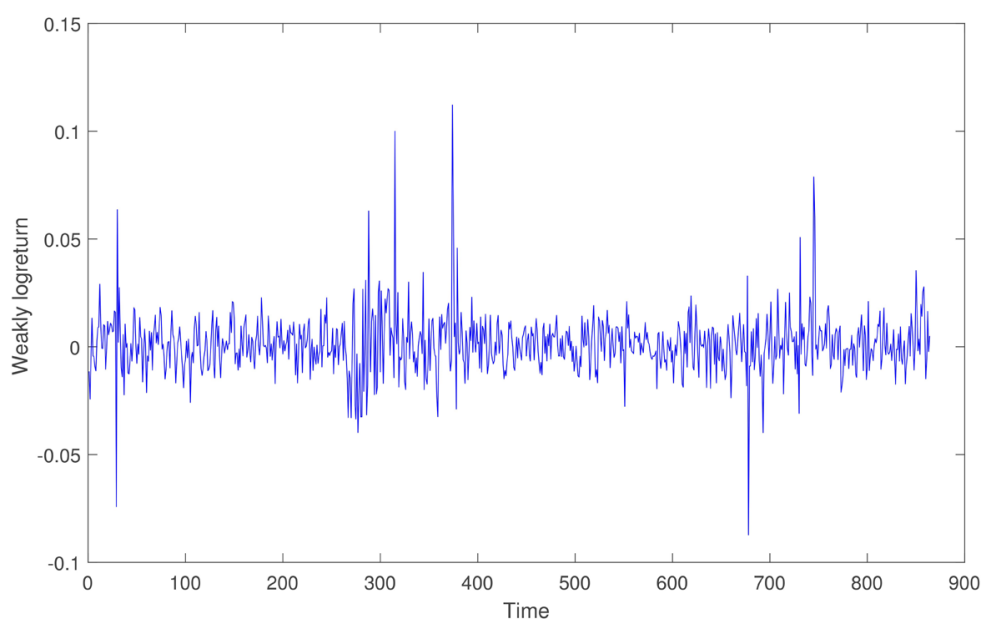

Figure 2. The weakly log return series. 


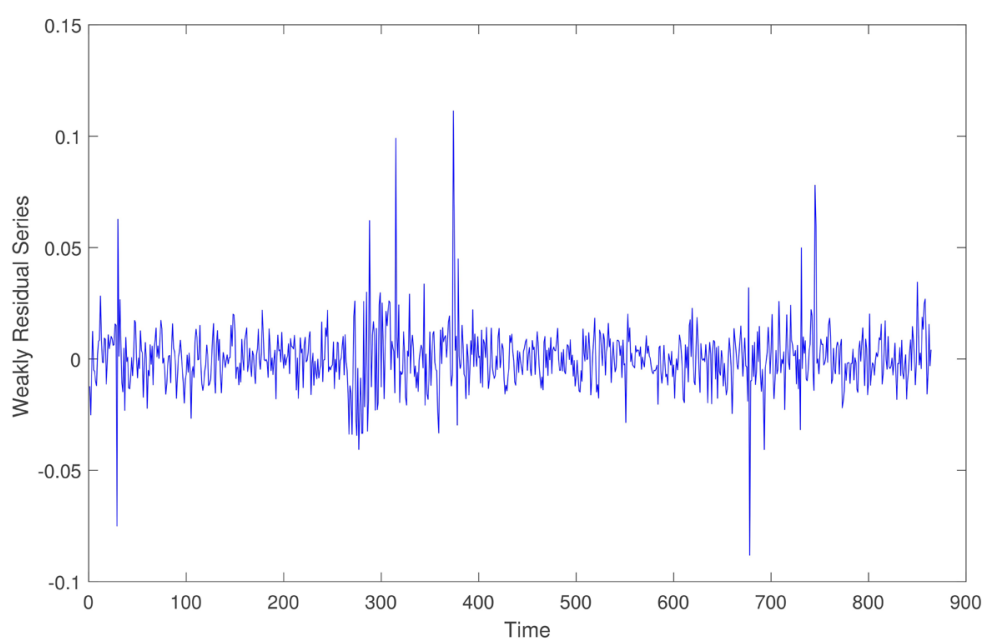

Figure 3. The residual series.

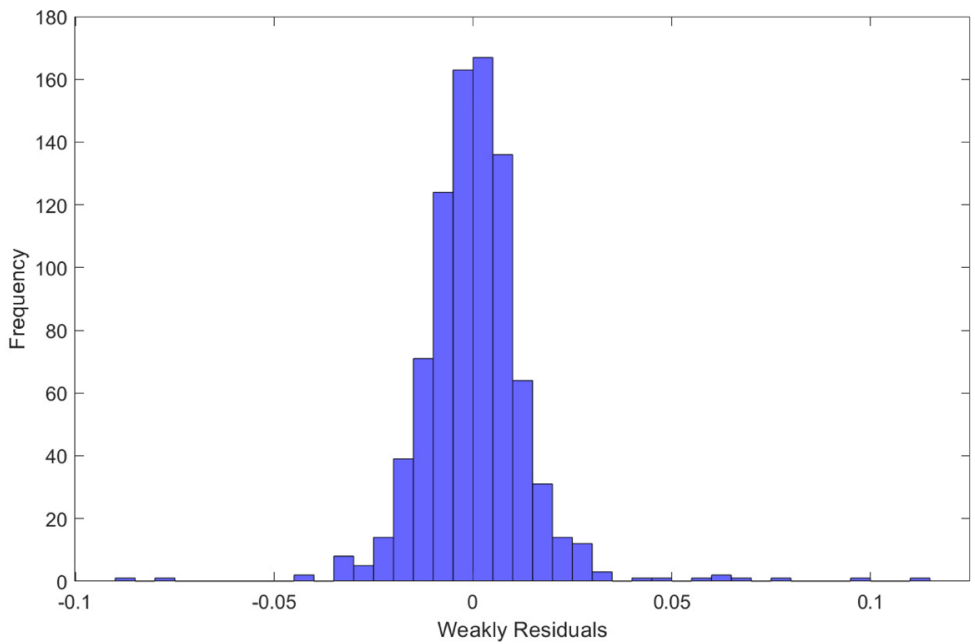

Figure 4. The histogram of the residual series.

To proceed to the parameters estimation of the Fuzzy-EGARCH-ANN model, only number of rules $(R)$ and the realized volatility are remaining to be determined. For our case, as mentioned earlier, $R$ is going to be determined by Subtractive clustering algorithm (SCA), and the realized volatility at time $t$ is the square root of the square of residual series at time $t$. As $R=3$ is obtained and the graph of the realized volatility is given by Figure 5 .

Therefore, for $p=1, q=2, m=2, s=1$, by JADE with Achieve the estimated parameter vector is given by Table 4 on page 15 . Plus this, the corresponding mean squared forecast errors (MSFE) value is 5.7150e-07.

Figure 6 is the figure that presents a summary and analysis of the MSFE obtained by JADE with Achieve during the parameter estimation of the proposed model.

Finally, Figure 7, and Figure 8 are the figures that presents a summary of estimated volatility by the proposed model for $T=800$, and validation for $T=864$, respectively. Here, the validation data set is the last 64 data points. 
Note: The Mean squared forecast error (MSFE) for this validation is $6.4176 \mathrm{e}-07$, which is very near to that of the Mean squared forecast error (MSFE) obtained during the parameter estimation time. In addition to this its corresponding MAE value is $\mathbf{1 . 3 2 8 6 \mathrm { e } - 0 4}$. Here, the model has fitted the data very well. As a result, the following forecasted values has obtained for different periods are given by Table 5.

Table 4. The estimated parameters of Fuzzy-EGARCH-ANN model on the first 800 simulated data points.

\begin{tabular}{cccccc}
\hline Parameters & Coefficients & Parameters & Coefficients & Parameters & Coefficients \\
\hline$E_{1}$ & -2.2342 & $E_{2}$ & -4.8185 & $E_{3}$ & -2.3790 \\
$\alpha_{11}$ & -0.0651 & $\alpha_{12}$ & 0.1157 & $\alpha_{13}$ & 0.3160 \\
$\gamma_{11}$ & 0.2112 & $\gamma_{12}$ & 0.8202 & $\gamma_{13}$ & -0.4657 \\
$\beta_{11}$ & 0.2495 & $\beta_{12}$ & 1.3179 & $\beta_{13}$ & 0.1111 \\
$\beta_{21}$ & 0.6169 & $\beta_{22}$ & -0.6989 & $\beta_{23}$ & 0.5320 \\
$\xi_{11}$ & -1.0617 & $\xi_{12}$ & -0.1719 & $\xi_{13}$ & 0.8446 \\
\hline
\end{tabular}

Table 5. 3 days ahead volatility prediction analysis of the Fuzzy-EGARCH-ANN(1, 2, 2, 1) model.

\begin{tabular}{|c|c|c|c|c|c|}
\hline $\begin{array}{c}\text { The last } 4 \text { realized } \\
\text { volatility value }\end{array}$ & $T=860$ & $T=861$ & $T=862$ & $T=863$ & $T=864$ \\
\hline $2.9852 \mathrm{e}-05$ & $8.8230 \mathrm{e}-05$ & & & & \\
\hline $2.8767 \mathrm{e}-05$ & $5.7015 \mathrm{e}-07$ & $3.5668 \mathrm{e}-05$ & & & \\
\hline 0.0064 & $1.1514 \mathrm{e}-09$ & $1.7548 \mathrm{e}-06$ & $1.6494 \mathrm{e}-05$ & & \\
\hline $8.4387 e-05$ & & $1.1406 \mathrm{e}-07$ & 0.0042 & $7.1457 \mathrm{e}-05$ & \\
\hline \multirow[t]{3}{*}{$1.6742 \mathrm{e}-05$} & & & 0.0166 & $2.3501 \mathrm{e}-05$ & $1.1993 \mathrm{e}-05$ \\
\hline & & & & $8.9092 \mathrm{e}-06$ & 0.0178 \\
\hline & & & & & 0.0476 \\
\hline
\end{tabular}

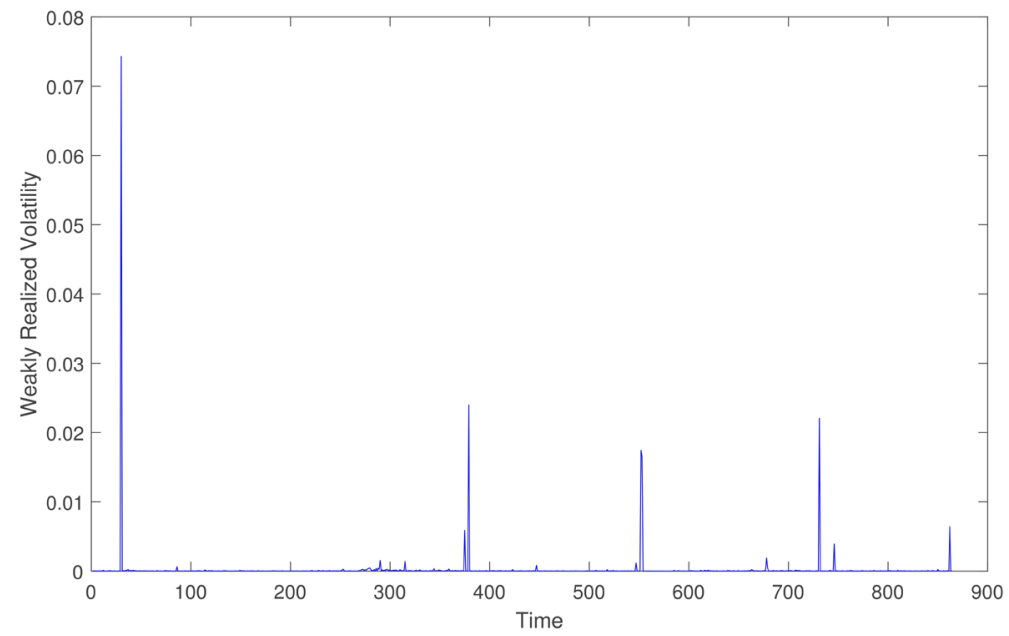

Figure 5. The realized volatility series. 


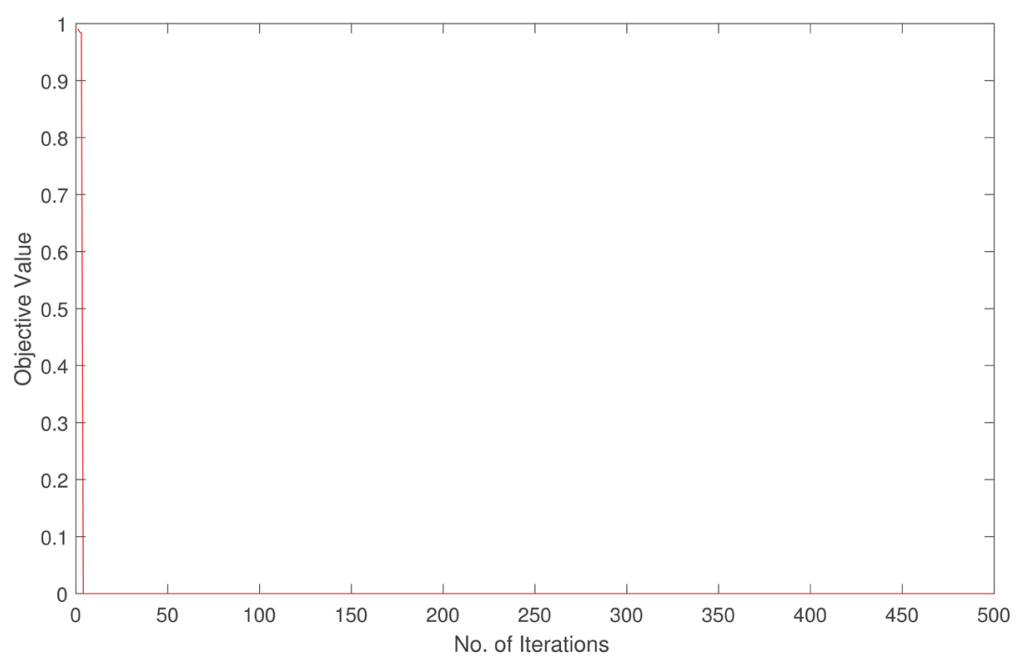

Figure 6. The MSFE obtained by JADE with archive.

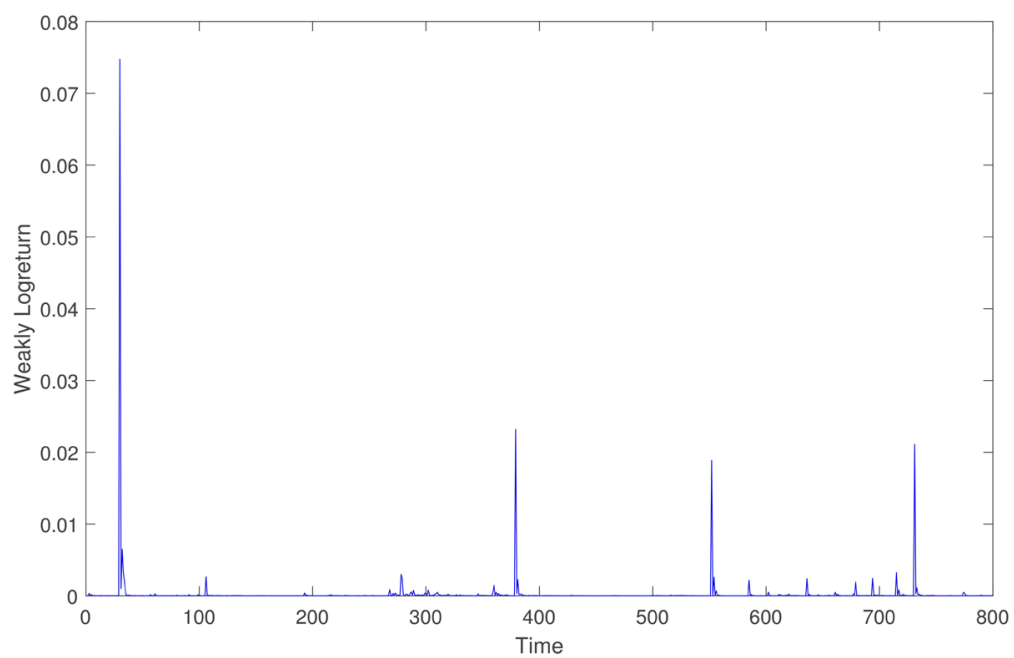

Figure 7. The estimated volatility for $T=800$.

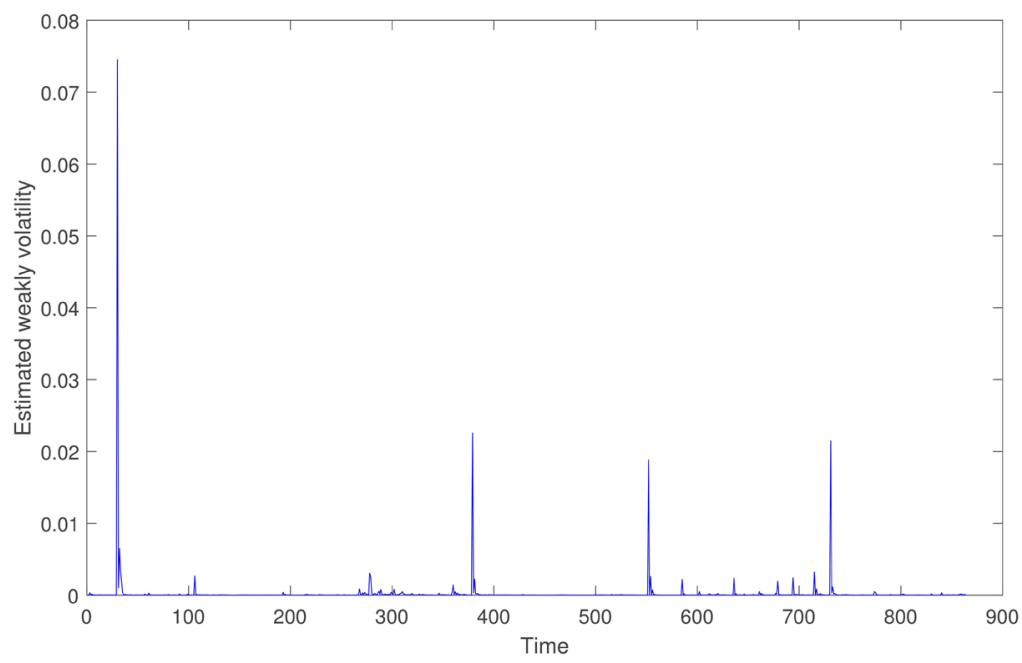

Figure 8. The validation of volatility for $T=864$. 


\section{Conclusion}

In this work, a robust analysis of volatility forecasting of the GBP-ETB exchange rate was provided using weekly data spanning the period June 30, 2003-January 24,2020 . To our knowledge, this was the first study that focuses on the GBP-ETB exchange rate using high-frequency data and the Fuzzy-EGARCH-ANN econometric model. The study documented evidence that Fuzzy-EGARCH-ANN(1, 2, 2, 1) with students $t$-distribution is found to perform best in terms of one-stepahead forecasting based on realized volatility calculated from the underlying daily data series. A one-step-ahead forecasted conditional variance of weekly GBP-ETB exchange rate portrays large spikes around 2010, 2018, and it is evident that weekly GBP-ETB exchange rates are volatile. These large spikes indicate devaluation of Ethiopian birr against the Great Britain Pound. This volatility behavior may affect the International Foreign Investment and trade balance of the country. Therefore, the research finds that the best performing model in terms of one-step ahead forecasts based on realized volatility computed from the underlying daily data series is the Fuzzy-EGARCH-ANN $(1,2,2,1)$ with students $t$-distribution.

\section{Author's Contributions}

Methodology, GELETA Mohammed; Conceptualization and Supervision, JANE Aduda and ANANDA Kube. Finally, all the authors have read and approved the final manuscript.

\section{Funding Statement}

Geleta T. Mohammed is the one going to pay the article processing charge from his monthly stipend.

\section{Data Availability Statement}

The Great Britain pound to Ethiopian Birr exchange rates data used to support the findings of this study are included within the supplementary information files.

\section{Conflicts of Interest}

The authors declare no conflicts of interest regarding the publication of this paper.

\section{References}

[1] Krugman, P., Obstfeld, M. and Melitz, M. (2012) International Economics, Theory and Policies. 9th Edition, Pearson Addison-Wesley, Boston, 321-495.

[2] Kamal, Y., Haq, M., Ghani, O. and Khan, M. (2012) Modeling the Exchange Rate Volatility, Using Generalized Autoregressive Conditionally Heteroscedastic (GARCH) Type Model: Evidence from Pakistan. African Journal of Business Management, 6, 2830-2838. https://doi.org/10.5897/AJBM10.1657 
[3] Abdella, S.Z. (2012) Modeling Exchange Rate Volatility Using GARCH Models. Empirical Evidence from Arab Countries. International Journal of Economics and Finance, 4, 216. https://doi.org/10.5539/ijef.v4n3p216

[4] Ramzan, K. (2012) Modeling and Forecasting Exchange Rate Dynamics in Pakistan Using ARCH Family of Models. Electronic Journal of Applied Statistical Analysis, 5, 15-29.

[5] Ayalew, S. (2012) Modeling Ethiopian Birr/Dollar Exchange Rate Volatility: Application of GARCH and Asymmetric Models. International Journal of Innovative Research and Development, 1, 160-190.

[6] de Dieu Ntawihebasenga, J., Mung'atu, J.K. and Mwita, P.N. (2015) Modeling the Volatility of Exchange Rates in Rwandese Markets. American Journal of Theoretical and Applied Statistics, 4, 426-431. https://doi.org/10.11648/j.ajtas.20150406.12

[7] Dickey, D.A. and Fuller, W.A. (1979) Distribution of the Estimators for Autoregressive Time Series with a Unit Root. Journal of the American Statistical Association, 79, 427-431. https://doi.org/10.1080/01621459.1979.10482531

[8] Phillips, P.C. and Perron, P. (1988) Testing for a Unit Root in Time Series Regression. Journal of Biomedicine, 75, 335-346. https://doi.org/10.1093/biomet/75.2.335

[9] Fufa, D.D. and Zeleke, B.L. (2018) Forecasting the Volatility of Ethiopian Birr/Euro Exchange Rate Using Garch-Type Models. Annals of Data Science, 5, 529-547. https://doi.org/10.1007/s40745-018-0151-6

[10] Bera, A.K. and Jarque, C.M. (1982) Model Specification Tests: A Simultaneous Approach. Journal of Economics, 20, 59-82. https://doi.org/10.1016/0304-4076(82)90103-8

[11] Mohammed, G.T., Aduda, J.A. and Kube, A.O. (2020) Improving Forecasts of the EGARCH Model Using Artificial Neural Network and Fuzzy Inference System. Journal of Mathematics, 2020, Article ID: 6871396. https://doi.org/10.1155/2020/6871396

[12] Dash, R. and Dash, P. (2016) An Evolutionary Hybrid Fuzzy Computationally Efficient EGARCH Model for Volatility Prediction. Applied Soft Computing, 45, 40-60. https://doi.org/10.1016/j.asoc.2016.04.014

[13] Tsay, R.S. (2005) Analysis of Financial Time Series (Vol. 543). John Wiley and Sons, Hoboken. https://doi.org/10.1002/0471746193

[14] Zhang, J. and Sanderson, A.C. (2009) JADE: Adaptive Differential Evolution with Optional External Archive. IEEE Transactions on Evolutionary Computation, 13, 945-958. https://doi.org/10.1109/TEVC.2009.2014613

[15] Andersen, T.G., Bollerslev, T., Diebold, F.X. and Labys, P. (2003) Modeling and Forecasting Realized Volatility. Econometrica, 71, 579-625. https://doi.org/10.1111/1468-0262.00418

[16] Bergdorf-Nielsen, O.E. and Shephard, N. (2004) Power and Power Variation with Stochastic Volatility and Jumps. Journal of Financial Economics, 2, 1-48. 